\title{
Electrostatic fine particles emitted from laser printers as potential vectors for airborne transmission of COVID-19
}

\author{
Shanshan $\mathrm{He}^{1} \cdot$ Jie $\operatorname{Han}^{1}$ (D) \\ Received: 21 July 2020 / Accepted: 1 August 2020 / Published online: 7 August 2020 \\ C) Springer Nature Switzerland AG 2020
}

\begin{abstract}
The COVID-19 pandemic caused by the severe acute respiratory syndrome coronavirus 2 (SARS-CoV-2) has infected more than 14 million people globally. Recently, airborne transmission has been postulated to be a major contributor to the spread of the novel coronavirus, especially in enclosed public spaces. While many studies have demonstrated positive correlations between atmospheric pollutants and SARS-CoV-2 infection, the impact of indoor air pollutants on airborne transmission has been largely overlooked. In particular, laser printers are a primary source of particle emission that increases the concentrations of particulate matter in indoor atmosphere by releasing substantial quantities of electrostatic fine particles, at rates comparable with tobacco smoking and incense burning. We hypothesized that particles emitted from laser printers present a potential risk factor for the transmission of SARS-CoV-2 in offices and other indoor environments with high user occupancy. To test this hypothesis, we reviewed recent knowledge on the characteristics of particles emitted by laser printing, including their emission rates and accumulation in indoor air, electrostatic charges, localized emission and subsequent particle diffusion in relation to the human breathing zone. We then discuss the potential impact on the transmission of SAR-CoV-2 in indoor spaces. We found that emission rates from laser printers ranged from $10^{8}$ to $10^{12}$ particles $\mathrm{min}^{-1}$, and these fine particles typically remain suspended for prolonged periods in indoor air. Electrostatic charges carried by these particles can reach 260-379 e per particle, thus enhancing their surface adsorption and deposition in human airways. Localized emission by laser printers and subsequent diffusion highly increase particle concentrations near the human breathing zone.
\end{abstract}

Keywords Particulate $\cdot$ Charge $\cdot$ Carrier $\cdot$ Lung $\cdot$ Deposition $\cdot$ Coronavirus

\section{Introduction}

Since the first report in December 2019, the novel coronavirus, Severe Acute Respiratory Syndrome Coronavirus 2 (SARS-CoV-2), has emerged in many parts of the world (Wang et al. 2020). At the time of writing July 29, 2020), there have been over 16.5 million confirmed cases around the globe (WHO 2020a). While the numbers of SARS$\mathrm{CoV}-2$ infection and mortality continue to increase, many countries and regions are reopening their economy on the back of a fragile recovery. Recently, airborne spread has been postulated as an important route of transmission in enclosed public spaces, which could lead to clustered

Jie Han

jiehan@xjtu.edu.cn

1 Department of Environmental Science and Engineering, Xi'an Jiaotong University, Xi' an 710049,

People's Republic of China infections with short periods of exposure (Morawskaa and Cao 2020). However, to this date, scientific communities and regulatory bodies have not made investigations on this particular transmission route a priority with policies and guidelines to mitigate risks in indoor environments (Lewis 2020). On July 6, 2020, in an open commentary, 239 scientists from 32 countries called for action from the World Health Organization (WHO) to update information on the airborne transmission of COVID-19 (Morawskaa and Milton 2020). A scientific brief was subsequently released by the agency, recognizing the urgency of this matter while outlining up-to-date evidence and knowledge gaps on this particular transmission route (WHO 2020b).

Various researchers indicated that airborne particles could play an important role in the transmission of respiratory pathogens (Lindsley et al. 2015; Qu et al. 2020; Riccò et al. 2020). Recent studies showed that SARS-CoV-2 could survive and remain infectious for hours to several days after being adsorbed on aerosols or deposited on surfaces (van 
Doremalen et al. 2020; Fears et al. 2020; Sharma et al. 2020). Recently, Setti et al. (2020) found that SARS-CoV-2 present on particulate matter showed increased persistence by forming clusters. In two retrospective studies, Zhu et al. (2020) and Fattorini and Regoli (2020) identified strong positive correlations between short-term and long-term particulate matter (PM2.5 and PM10) concentrations versus the daily confirmed cases of SARS-CoV-2 infection, respectively. These findings were consistent with the earlier conclusion that both long-term and short-term exposures to elevated levels of air pollutants were closely correlated with higher infection rates by respiratory pathogens (Riccò et al. 2020).

It is noteworthy that recent studies and discussions have invariably focused on the correlations between outdoor atmospheric pollutants and SARS-CoV-2 infection (Conticini et al. 2020; Domingo and Rovira 2020; Fattorini and Regoli 2020), while the impact of indoor air pollutants on the transmission of SARS-CoV-2, especially in enclosed public spaces such as building and offices, has been widely neglected (Lewis 2020). Various researchers postulated that indoor particulate matter emitted by activities such as tobacco smoking and incense burning could facilitate the transmission of SARS-CoV-2 in indoor environments (Amoatey et al. 2020; Mahabee-Gittens et al. 2020). In fact, many studies have shown that emissions from office equipment constitute a major source of indoor air pollutants (Destaillats et al. 2008). A survey in 62 German offices found that concentrations of particulate matter ranged from 19.1 to $231 \mathrm{\mu g} \mathrm{m}^{-3}$ during their normal working hours (Tang et al. 2012). In a comprehensive review, Destaillats et al. (2008) showed that office equipment (i.e., printers, copy machines, computers, and other electronic devices) was a significant source of volatile and semivolatile organic chemicals, ozone, and particulate matter in indoor spaces including offices, schools, and residences. Zhang et al. (2017) identified the common contributors of PM2.5 in typical work environments including office machines, air conditioners, photocopiers, and printers, where emissions from printing and tobacco smoking were found to be the most significant sources.

Laser printers were found to be the main source of particulate matter in office buildings where tobacco smoking is prohibited (He et al. 2007). Air monitoring data in a $120 \mathrm{~m}^{2}$ office in the central business district of Brisbane showed the highest indoor particle concentration of $38.2 \times 10^{3}$ particles $\mathrm{cm}^{-3}$ with printers operating, which was several times higher than the average $\left((6.5 \pm 8.2) \times 10^{3}\right.$ particles $\left.\mathrm{cm}^{-3}\right)$ recorded during other periods (He et al. 2007). The significant quantities of particulate matter emitted by laser printers could render effects on the airborne transmission of pathogens in indoor spaces, for instance, by facilitating their diffusion and acting as vectors as those identified on outdoor atmospheric particulates. Here, we review the recent knowledge on the characteristics of particle emissions from laser printers by focusing on their emission rates, quantities, and electrostatic charges. Where applicable, comparisons were made with other common sources of particle emissions found in indoor air. Further, we assessed the potential implications of printer emissions on airborne transmission of pathogens by highlighting existing data and evidence on: (1) enhanced adsorption of pathogens on charged surfaces and particles; (2) increased deposition of charged particles in human airways; and (3) localized particle emission by laser printers in relation to the human breathing zone.

\section{Particle emission from laser printing}

The root cause of particle emission by laser printers is the incomplete material transfer between charged toner drum and paper surface (Lee et al. 2001). Typically, about $75 \%$ of toner materials are transferred effectively to the photoconductive drum, and what does not adhere to the drum becomes available for emission to air (Lee et al. 2001). Figure 1 summarizes data from chamber experiments on particle emission rates by laser printing, in comparison with those generated by tobacco smoking and incense burning (Chen et al. 2018; He et al. 2007, 2010; Salthammer et al. 2012; Scungio et al. 2017; Sung et al 2017; Wallace and Ott 2011; Wu et al. 2012). The data demonstrate that particle emission rates from laser printers widely differed in studies, and even data reported in the same study under the same settings could differ by more than two orders of magnitudes. For instance, Scungio et al. (2017) found that emission rates ranged between $3.4 \times 10^{8}$ and $1.6 \times 10^{12}$ particles $\min ^{-1}$ from different laser printers $(n=110)$ when printing 50 pages with a monochromatic toner coverage $(5 \%)$ on each page. He et al. (2010) also demonstrated that emission rates from 30 laser printers ranged from $(4.25 \pm 2.10) \times 10^{9}$ to $(3.3 \pm 0.64) \times 10^{12}$ particles $\min ^{-1}$ using a $5 \%$ monochromatic toner coverage on each page. Differences in laser printers in terms of their particle emission level may be the main cause of the wide disparity in the reported data. To demonstrate this, He et al. (2007) measured the particle concentration after each printer printed one page and compared it with the background concentration in each office environment where the printer was located and ranked those printers into four different classes based on the calculated concentration ratios. The study found that about $60 \%, 13 \%$, and $27 \%$ of the tested printers $(n=62)$ were non-emitters (ratios $<1)$, low (ratios $=1-5$ ) and median (ratios $=5-10)$ emitters, and high emitters (ratio $>10$ ), respectively.

By further comparing particle emission rates by different indoor human activities, it is evident that particles emitted from laser printers could reach comparable levels to those generated by indoor incense burning, which could range 


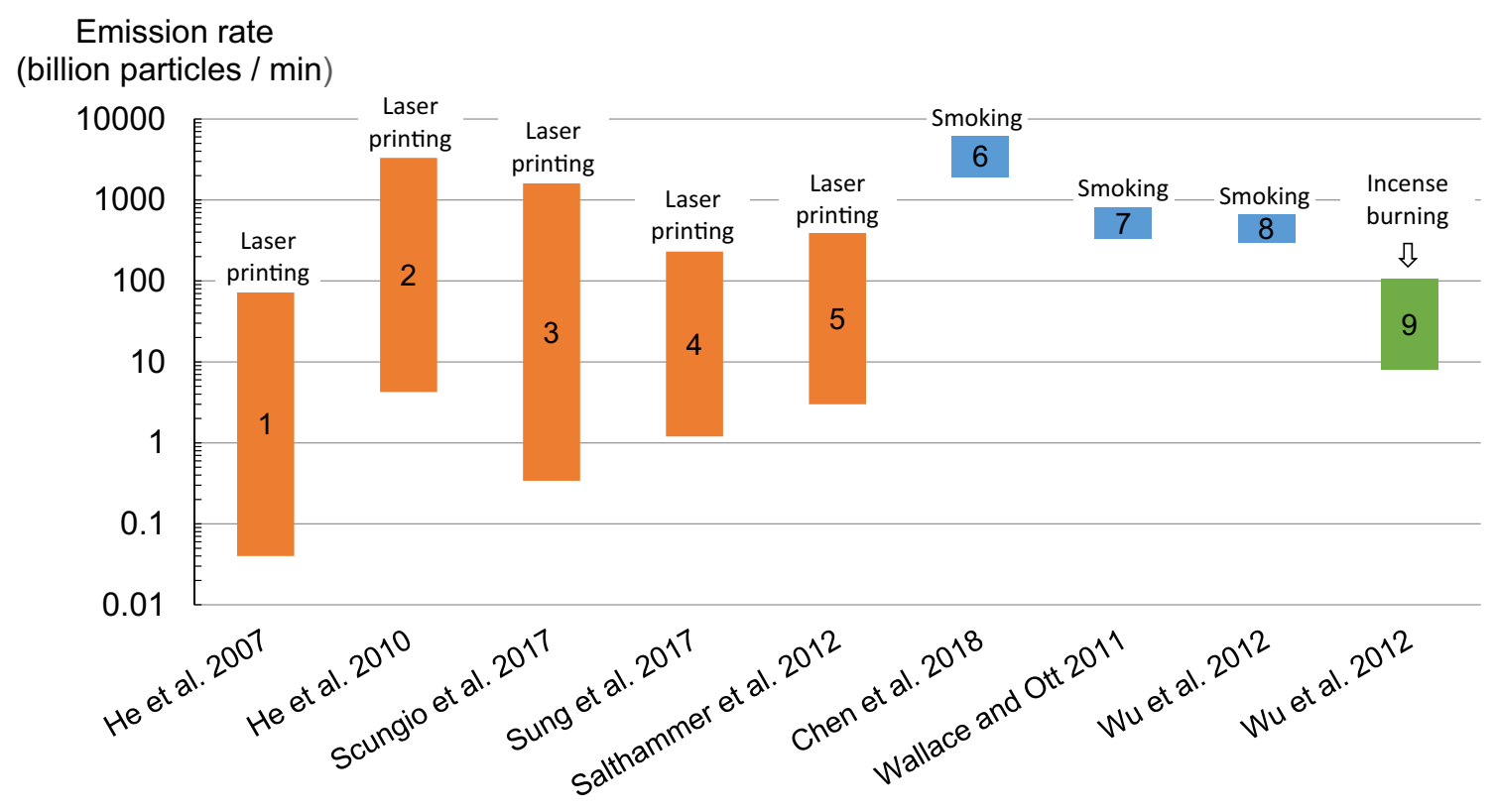

Fig. 1 Bar graphs comparing particle emission rates from laser printing, tobacco smoking, and incense burning. Data were compiled from published studies with citations given below data bars. For laser printing, studies 1-3 used monochrome printing with a toner coverage of 5\%, while studies 4 and 5 additionally used color printing with a toner coverage of $20 \%$. All data were obtained by chamber experi-

between $(0.08 \pm 0.01) \times 10^{11}$ and $(0.99 \pm 0.08) \times 10^{11}$ particles $\mathrm{min}^{-1}$, with a mean emission rate of $(0.44 \pm 0.33) \times 10^{10}$ particles $\mathrm{min}^{-1}$ from five types of incense (Wu et al. 2012). Notably, the upper bands of particle emission rates from laser printers are similar to those typically reported on indoor tobacco smoking, which were found to be in the range of $(3.01 \pm 0.29) \times 10^{11}$ to $4.27 \times 10^{12}$ particles $\mathrm{min}^{-1}$ depending on the method used for collecting the exhaled smoke (Chen et al. 2018; Wallace and Ott 2011; Wu et al. 2012).

In a field study, Lee and Hsu (2007) reported that indoor PM2.5 concentrations at 12 photocopy centers in Taiwan increased by as much as $10-83 \mu \mathrm{g} \mathrm{m}^{-3}$ during their operating hours compared with levels measured before operation Tang et al. (2012) reported that about $70 \%$ of the offices they surveyed in Germany $(n=63)$ showed significant increases in levels of indoor particulate matter $(0.23-20 \mu \mathrm{m})$ after laser printing, where their median indoor PM2.5 concentration increased by $12 \mu \mathrm{g} \mathrm{m}^{-3}$ after printing 500 pages under normal settings. Once released to air, these fine particles could remain airborne for hours in an undisturbed indoor environment. Shi et al. (2015) found that particle concentrations attenuated very slowly in a $1.0 \mathrm{~m}^{3}$ chamber after printing ended, requiring $2.5 \mathrm{~h}$ to attain a tenfold decrease from $10^{5}$ to $10^{4}$ particles $\mathrm{cm}^{-3}$. These findings indicate that fine particles emitted by laser printers can remain airborne for prolonged periods and accumulate over time to reach significant levels in indoor air. ments except study 6 which reported data from field measurements. Emission rates from laser printing differed widely, partly because of differences in emission levels by different laser printers. It is also evident that particles emitted by laser printers could reach comparable rates to those generated by indoor incense burning and tobacco smoking

Recently, Zhu et al. (2020) used the Generalized Additive Model with a Gaussian distribution family to study the cumulative lag effect of ambient air pollutants on SARSCoV-2 infection (Fig. 2). The retrospective analysis identified significant positive correlations between moving-average concentrations of air pollutants, including particulate matter (PM2.5 and PM10), and normalized daily confirmed cases of SARS-CoV-2 infections in 120 cities in China between January 23, 2020, and February 29, 2020 (Zhu et al. 2020). In the same vein, Fattorini and Regoli (2020) revealed that long-term air quality data on PM2.5 significantly correlated with cases of SARS-CoV-2 in 71 Italian provinces, providing further evidence that atmospheric particulate matter presented a favorable medium for SARS-CoV-2 transmission in the environment. The existing evidence leads to the postulation that the significant quantities of fine particles emitted by laser printers may lead to similar effects in indoor environments, especially in enclosed public spaces with high user occupancy such as offices, schools, libraries, and information commons.

\section{Enhanced surface adsorption and particle deposition of charged particles}

One unique characteristic of particles emitted by laser printers is that they carry substantial amounts of electrostatic charges that could also persist in air. Particles 

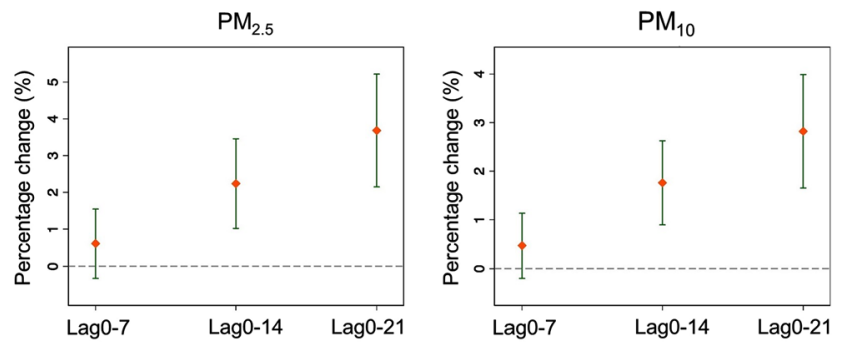

$\mathrm{SO}_{2}$
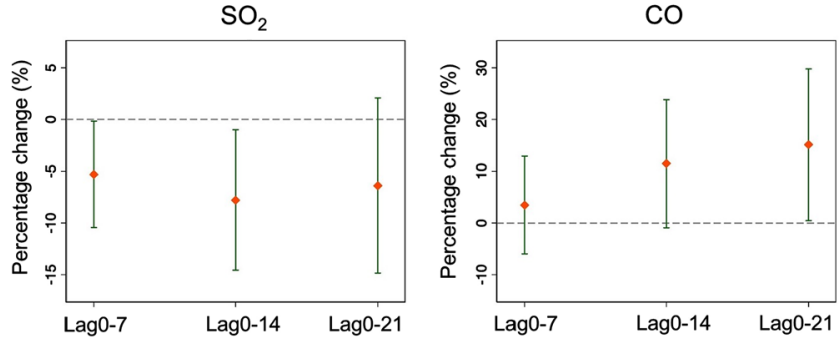

$\mathrm{NO}_{2}$
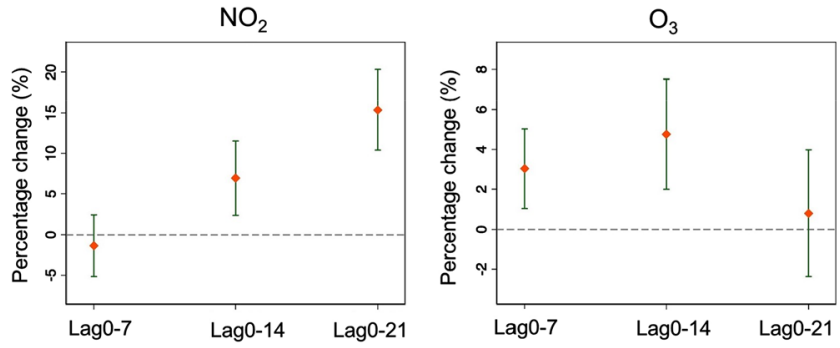

Fig. 2 Correlation between percentage change (\%) in daily COVID19 confirmed cases per unit increase in pollutant concentration in 120 Chinese cities between January 23, 2020, and February 29, 2020. Unit increase is defined as $10 \mu \mathrm{g} / \mathrm{m}^{3}$ for particulate matter (PM2.5 and $\mathrm{PM} 10), \mathrm{SO}_{2}, \mathrm{NO}_{2}$, and $\mathrm{O}_{3}$, or $1.0 \mathrm{mg} / \mathrm{m}^{3}$ for CO. $\mathrm{Lag} 0$-n denotes the $(n+1)$-day moving average of air pollutant concentrations to capture the cumulative lag effect of air pollution on COVID-19 infection. Significantly positive associations were observed on PM2.5, PM10, $\mathrm{CO}, \mathrm{NO}_{2}$, and $\mathrm{O}_{3}$ concentrations with normalized confirmed cases of COVID-19. Reprinted with permission of Elsevier from Zhu et al. (2020)

released from laser printer are generally charged by the diffusion charging mechanism of corona devices installed in these printers (Lee and Hsu 2007). Jiang and $\mathrm{Lu}$ (2010) found that the average surface charge of particles emitted from laser printers is in the range of $4.16 \times 10^{-17}-6.07 \times 10^{-17} \mathrm{C}(\sim 260-379$ e). Jayaratne et al. (2012) monitored the temporal variation of charged particle concentrations in laser printer emissions. The study found that about $60 \%$ of the initial charges remained on those particles after being released into the indoor atmosphere for ten minutes. It is noteworthy that contemporarily designed face masks and particulate respirators also rely on electrostatic charges to capture small droplets and particles in air. These electret filters, mostly constructed by polypropylene microfibers with electrostatic charges, attract particulates passing by via Coulombic attraction and dielectrophoresis (Romay et al. 1998). Allen et al. (2006) found that airborne microorganisms could be easily attracted and adhered on charged surfaces via electrostatic interactions. The study found that $82.6 \%$ more viable bacteria were deposited onto polyethylene plastic aprons with electrostatic charges loaded on surfaces, compared with an increase of only $16.7 \%$ on conducting aluminum foil aprons under same conditions. Górny et al. (2018) reported that fibrous aerosols with electrostatic charges were able to transport up to 160 viable microorganisms per fiber in both dry and humid air, at a relative humidity below $30 \%$ and above $60 \%$, respectively. Virus-laden aerosols, droplets, and droplet nuclei may be attracted to charged particles emitted from laser printers via similar mechanisms.

Electrostatic charges on particles also have a significant impact on their deposition in lungs (Koullapis et al. 2016). For charged fine particles, enhanced particle deposition takes place in lungs via two processes including the space charge effects and image charge forces (Majid et al. 2012). Large eddy simulations were used to investigate the deposition of inhaled fine particles in a realistic geometry of human airways reconstructed from computed tomography (CT) scans (Koullapis et al. 2016). Figure 3 illustrates the fractions of particle deposition at mouth-throat, trachea, left lung, right lung, and the overall deposition obtained in their study at an inhalation flow rate of $15.2 \mathrm{~L} \mathrm{~min}^{-1}$. The deposition of charged particles with intermediate sizes $(0.5$ and $1.0 \mu \mathrm{m})$ followed similar trends to these shown in Fig. 3. Notably, the study found that the deposition fraction of small particles $(0.1-2.5 \mu \mathrm{m})$ carrying 1000 elementary charges in human airways is about 1.5-7.0 times greater than those of the same size and without electrical charges. Voliotis et al. (2017) modeled the deposition of electrostatic fine particles emitted from printers in the human respiratory tract using stochastic lung models, by applying the typical breathing conditions of an adult male under light exercise activities. The study estimated that average deposition rates were generally higher than $2.0 \times 10^{7}$ particles $\mathrm{min}^{-1}$ in human lungs, and maximum deposition density was observed at the lobar bronchi at $1.5 \times 10^{8}$ particles $\mathrm{cm}^{-2}$. In a recent viewpoint article, $\mathrm{Qu}$ et al. (2020) pointed out that inhaling virus-carrying fine particles could transport these into the deeper alveolar and tracheobronchial regions, which could increase the likelihood of viral infection. Since particles emitted from laser printers carry substantial electrostatic charges from the printing process (Jayaratne et al. 2012), a further question arises as to whether these charged fine particles have higher deposition rates in lungs than electrically neutral particulate matter and thereby increase the chance of virus transmission, once they become the airborne carriers of SARS-CoV-2. 
Fig. 3 Influence of electrostatic charges on particle deposition with different charge levels in silico models of human airways, including mouth-throat, tracheal, left lung, right lung, and overall deposition, at an inhalation rate of $15.2 \mathrm{~L} \mathrm{~min}^{-1}$. Data suggest that electrostatic charges on particles significantly enhance their deposition in human airways, including lungs. The deposition of small particles carrying elementary charges is several times greater than those of the same size without electrical charges. Reprinted with permission of Elsevier from Koullapis et al. (2016)

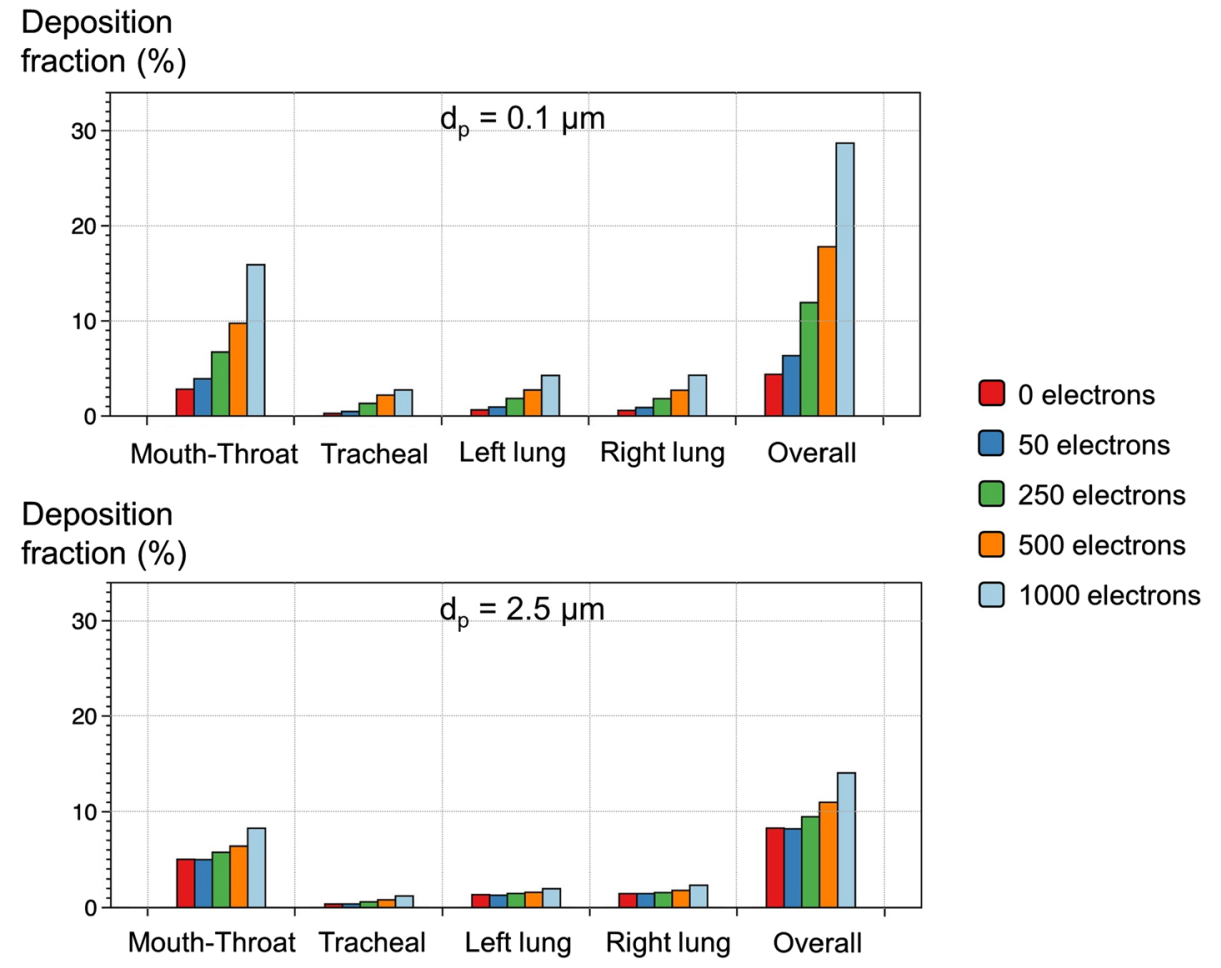

\section{Localized emission and particle distribution in relation to the human breathing zone}

As point sources, laser printers generate localized emissions with dramatically higher particle concentrations often at spots that are in close proximity to the user's mouth and nose. Kagi et al. (2007) measured particle concentrations around a desktop printer and identified the highest concentration of emitted particles at $\sim 0.4 \mathrm{~m}$ above the printer. When a user is in presence, the elevated body temperature creates thermal plume flows, drawing particles from ambient air toward the body in presence. Ansaripour et al. (2016) modeled the distribution of printer emission particles in the breathing zone of a manikin which was placed in proximity to a laser printer ( $0.4 \mathrm{~m}$ away from and $0.4 \mathrm{~m}$ above) in a ventilated room.Figure 4 compares the temporal profiles of particle concentrations measured around the heated and unheated manikin with a displacement ventilation system operating in the cubicle. The study found that the average particle concentration was six times higher in the breathing zone of the heated manikin $\left(32.2{ }^{\circ} \mathrm{C}\right)$ compared with the unheated one three minutes after the printing began. The proximity of these particles to the human breathing zone increases their likelihood of contact with respiratory pathogens in the exhaled breath of users. During the early outbreak in Wuhan, China, Ye et al. (2020) detected the presence of SARS-CoV-2 on items commonly used in healthcare premises at the Zhongnan Hospital, where printers were identified as the most frequently contaminated object. Given that laser printers are used extensively in offices, schools, libraries, and information commons, often as shared facilities with frequent contact by different users, such pattern of use and their localized particle emission near the human breathing zone greatly increase the chance of contact between the viruses and particles emitted by laser printers (Fig. 5).

\section{Conclusion}

Electrostatic fine particles emitted from laser printers present a neglected risk factor on the airborne transmission of SARS-CoV-2 in indoor environments during the current pandemic. Laser printers have long been identified as a primary source of particle emissions in indoor spaces, particularly in office buildings where tobacco smoking is prohibited. Depending on the printer model and usage, large quantities of electrostatic fine particles can be emitted during laser printing, some at comparable rates generated by indoor incense burning and smoking. Once released to air, these fine particles can stay airborne for prolonged periods with very slow attenuation in calm indoor air and accumulate over time to reach significant levels. Electrostatic charges carried on these fine particles can enhance the adsorption of airborne pathogens on their surfaces as well as their own deposition in human lungs. Further, the localized particle emissions near the human breathing zone increase their chance of contact with respiratory pathogens in exhaled 
Fig. 4 Temporal distribution profiles of particles emitted from a desktop laser printer near a heated $\left(32.2^{\circ} \mathrm{C}\right)$ and an unheated human manikin in a modelled room with a displacement ventilation system operating at an inlet velocity of $0.2 \mathrm{~m} \mathrm{~s}^{-1}$. Note the significantly higher particle concentrations in the breathing zone of the heated manikin compared with the unheated one after printing began. Reprinted with permission of Elsevier from Ansaripour et al. (2016)

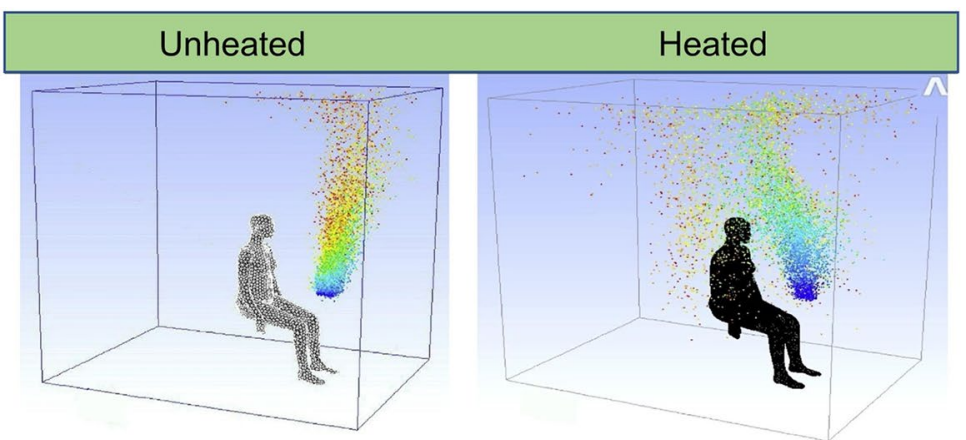

25 seconds
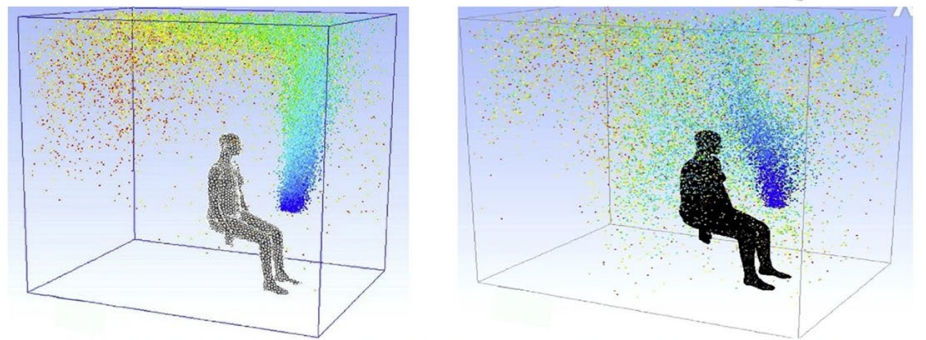

75 seconds
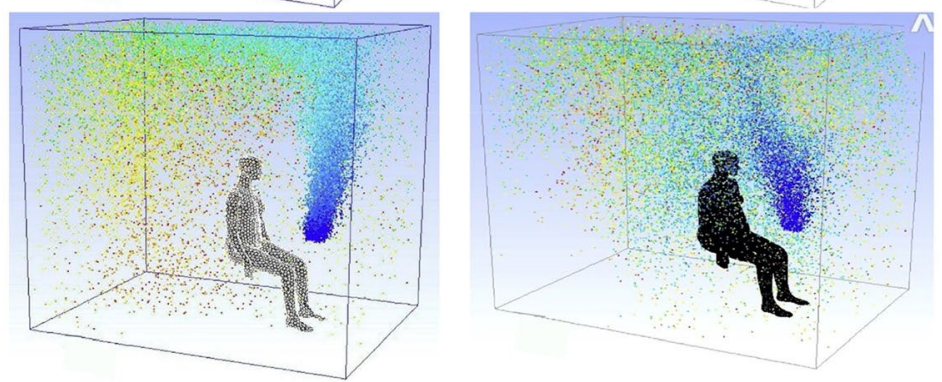

130 seconds

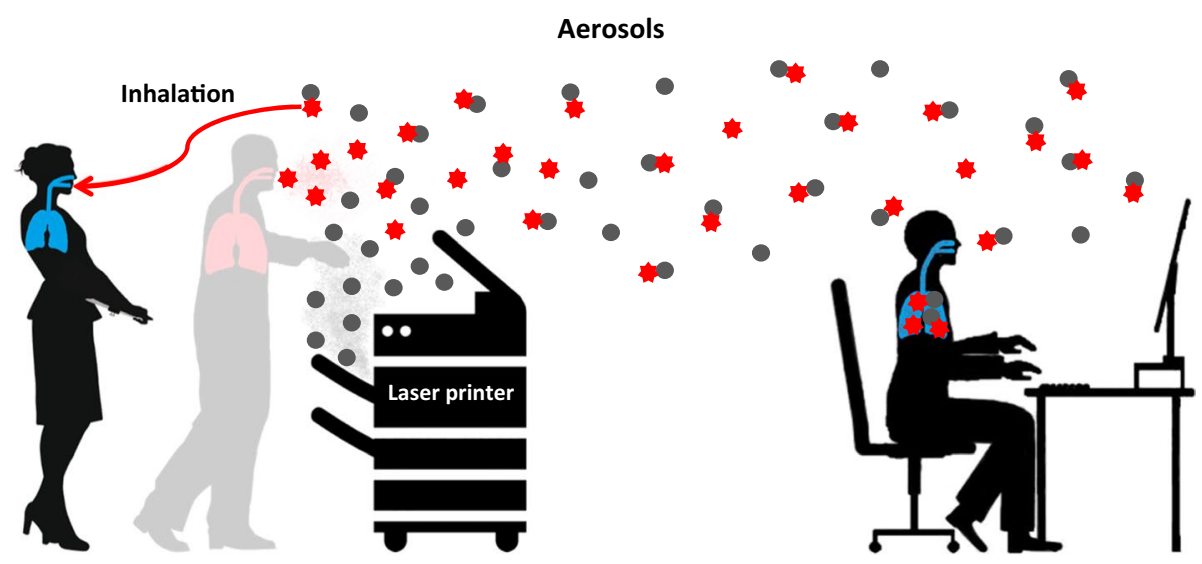

Fig. 5 A schematic illustration of charged particles emitted from laser printers as vectors for the airborne transmission of respiratory viruses in office environments. Laser printers are a main source of particulate matter in indoor air. These fine particles carry electrostatic charges and can remain airborne for long periods in the indoor atmosphere.
Localized emissions create hot spots with high particle concentrations in proximity to user's mouth and nose. Frequent contact by different users in public spaces increases the likelihood of contact between viruses in human breath and particles emitted from laser printers 
human breath, rendering them as potential vectors for the airborne transmission of SARS-CoV-2 in public spaces with laser printers operating. To mitigate the associated risks, we recommend that laser printers should be placed in separate, ventilated rooms while being kept away from people in enclosed public spaces. Where possible, paperless working should be encouraged to minimize printer emission and human-printer contact.

Acknowledgements This work was funded by the "Young Talent Support Plan" of Xi' an Jiaotong University. The authors wish to thank Professor Eric Lichtfouse at Aix-Marseille University for his inputs and many helpful suggestions through this work.

\section{Compliance with ethical standards}

Conflict of interest The authors declared that they have no conflict of interest.

\section{References}

Allen JE, Close JJ, Henshaw DL (2006) Static electric fields as a mediator of hospital infection. Indoor Built Environ 15(1):49-52. https ://doi.org/10.1177/1420326X06061502

Amoatey P, Omidvarborna H, Baawain MS, Al-Mamun A (2020) Impact of building ventilation systems and habitual indoor incense burning on SARS-CoV-2 virus transmissions in Middle Eastern countries. Sci Total Environ 733(1):139356. https://doi. org/10.1016/j.scitotenv.2020.139356

Ansaripour M, Abdolzadeh M, Sargazizadeh S (2016) Computational modeling of particle transport and distribution emitted from a Laserjet printer in a ventilated room with different ventilation configurations. Appl Therm Eng 103(25):920-933. https://doi. org/10.1016/j.applthermaleng.2016.04.137

Chen C, Zhao Y, Zhao B (2018) Emission rates of ultrafine and fine particles generated from human smoking of Chinese cigarettes. Atmos Environ 194:7-13. https://doi.org/10.1016/j.atmos env.2018.09.014

Conticini E, Frediani B, Caro D (2020) Can atmospheric pollution be considered a co-factor in extremely high level of SARS-CoV-2 lethality in Northern Italy? Environ Pollut 261:114465. https:// doi.org/10.1016/j.envpol.2020.114465

Destaillats H, Maddalena RL, Singer BC, Hodgson AT, McKone TE (2008) Indoor pollutants emitted by office equipment: A review of reported data and information needs. Atmos Environ 42(7):13711388. https://doi.org/10.1016/j.atmosenv.2007.10.080

Domingo JL, Rovira J (2020) Effects of air pollutants on the transmission and severity of respiratory viral infections. Environ Res 187:109650. https://doi.org/10.1016/j.envres.2020.109650

Doremalen N, Bushmaker T, Morris DH, Holbrook MG, Gamble A, Williamson BN, Tamin A, Harcourt JL, Thornburg NJ, Gerber SI, Lloyd-Smith JO, Wit E, Munster VJ (2020) Aerosol and surface stability of SARS-CoV-2 as compared with SARS-CoV-1. New Eng J Med 382:1564-1567. https://doi.org/10.1056/NEJMc 2004973

Fattorini D, Regoli F (2020) Role of the chronic air pollution levels in the Covid-19 outbreak risk in Italy. Environ Pollut 264:114732. https://doi.org/10.1016/j.envpol.2020.114732

Fears SC, Klimstra WB, Duprex P, Hartman A, Weaver SC, Plante KS et al (2020) Persistence of Severe Acute Respiratory
Syndrome Coronavirus 2 in aerosol suspensions. Emerg Infect Dis. https://doi.org/10.3201/eid2609.201806

Górny RL, Golofit-Szymczak M, Cyprowski M, Stobnicka A, Ławniczek-Wałczyk A (2018) Effect of electrical charges on potential of fibers for transport of microbial particles in dry and humid air. J Aerosol Sci 116:66-82. https://doi.org/10.1016/j. jaerosci.2017.11.003

He C, Morawska L, Taplin L (2007) Particle emission characteristics of office printers. Environ Sci Technol 41(17):6039-6045. https ://doi.org/10.1021/es063049z

He C, Morawska L, Wang H, Jayaratne R, McGarry P, Johnson GR, Bostrom T, Gonthier J, Authemayou S, Ayoko G (2010) Quantification of the relationship between fuser roller temperature and laser printer emissions. J Aerosol Sci 41(6):523-530. https ://doi.org/10.1016/j.jaerosci.2010.02.015

Jayaratne ER, Ling X, He C, Morawska L (2012) Monitoring charged particle and ion emissions from a laser printer. J Electrostat 70(3):333-338. https://doi.org/10.1016/j.elstat.2012.04.006

Jiang H, Lu L (2010) Measurement of the surface charge of ultrafine particles from laser printers and analysis of their electrostatic force. Atmos Environ 44(28):3347-3351. https://doi. org/10.1016/j.atmosenv.2010.06.025

Kagi N, Fujii S, Horiba Y, Namiki N, Ohtanic Y, Emi H, Tamurad H, Kim YS (2007) Indoor air quality for chemical and ultrafine particle contaminants from printers. Build Environ 42(5):1949_ 1954. https://doi.org/10.1016/j.buildenv.2006.04.008

Koullapis PG, Kassinos SC, Bivolarova MP, Melikov AK (2016) Particle deposition in a realistic geometry of the human conducting airways: effects of inlet velocity profile, inhalation flowrate and electrostatic charge. J Biomech 49(11):2201-2212. https://doi. org/10.1016/j.jbiomech.2015.11.029

Lee CW, Hsu DJ (2007) Measurements of fine and ultrafine particles formation in photocopy centers in Taiwan. Atmos Environ 41(31):6598-6609. https://doi.org/10.1016/j.atmos env.2007.04.016

Lee SC, Lam S, Fai HK (2001) Characterization of VOCs, ozone, and PM10 emissions from office equipment in an environmental chamber. Build Environ 36(7):837-842. https://doi.org/10.1016/ S0360-1323(01)00009-9

Lewis D (2020) Mounting evidence suggests coronavirus is airborne-but health advice has not caught up. Nature. https://doi. org/10.1038/d41586-020-02058-1

Lindsley WG, Noti JD, Blachere FM, Thewlis RE, Martin SB, Othumpangat S, Noorbakhsh B, Goldsmith WT, Vishnu A, Palmer JE, Clark KE, Beezhold DH (2015) Viable influenza a virus in airborne particles from human coughs. J Occup Environ Hyg 12(2):107-113. https://doi.org/10.1080/15459624.2014.973113

Mahabee-Gittens EM, Merianos AL, Matt GE (2020) Letter to the Editor Regarding: "An imperative need for research on the role of environmental factors in transmission of novel coronavirus (COVID-19)" secondhand and thirdhand smoke as potential sources of COVID-19. Environ Sci Technol 54(9):5309-5310. https://doi.org/10.1021/acs.est.0c02041

Majid H, Madl P, Hofmann W, Alam K (2012) Implementation of charged particles deposition in stochastic lung model and calculation of enhanced deposition. Aerosol Sci Technol 46(5):547554. https://doi.org/10.1080/02786826.2011.645957

Morawskaa L, Cao J (2020) Airborne transmission of SARS-CoV-2: the world should face the reality. Environ Int 139:105730. https ://doi.org/10.1016/j.envint.2020.105730

Morawskaa L, Milton DK (2020) It is time to address airborne transmission of COVID-19. Clin Infect Dis. https://doi.org/10.1093/ $\mathrm{cid} / \mathrm{ciaa} 939$

Qu G, Li X, Hu L, Jiang G (2020) An imperative need for research on the role of environmental factors in transmission of novel 
coronavirus (COVID-19). Environ Sci Technol 54(7):37303732. https://doi.org/10.1021/acs.est.0c01102

Riccò M, Ranzieri S, Balzarini F, Bragazzi NL, Corradi M (2020) SARS-CoV-2 infection and air pollutants: correlation or causation? Sci Total Environ 734(10):139489. https://doi.org/10.1016/j. scitotenv.2020.139489

Romay FJ, Liu BYH, Chae SJ (1998) Experimental study of electrostatic capture mechanisms in commercial electret filters. Aerosol Sci Technol 28(3):224-234. https://doi.org/10.1080/0278682980 8965523

Salthammer T, Schripp T, Uhde E, Wensing M (2012) Aerosols generated by hardcopy devices and other electrical appliances. Environ Pollut 169:167-174. https://doi.org/10.1016/j.envpol.2012.01.028

Scungio M, Vitanza T, Stabile L, Buonanno L, Morawska L (2017) Characterization of particle emission from laser printers. Sci Total Environ 586(15):623-630. https://doi.org/10.1016/j.scito tenv.2017.02.030

Setti L, Passarini F, Gennaro GD, Barbieri P, Perrone MG, Borelli M, Palmisani J, Gilio AD, Torboli V, Pallavicini A, Ruscio M, Piscitelli P, Miani A (2020) SARS-CoV-2 RNA found on particulate matter of Bergamo in Northern Italy: first preliminary evidence. Environ Res 188:109754. https://doi.org/10.1016/j. envres.2020.109754

Sharma VK, Jinadatha C, Lichtfouse E (2020) Environmental chemistry is most relevant to study coronavirus pandemics. Environ Chem Lett 18:993-996. https://doi.org/10.1007/s10311-02001017-6

Shi X, Chen R, Huo L, Zhao L, Bai R, Long D, Pui DYH, Rang W, Chen C (2015) Evaluation of nanoparticles emitted from printers in a clean chamber, a copy center and office rooms: health risks of indoor air quality. J Nanosci Nanotechnol 15:9554-9564. https ://doi.org/10.1166/jnn.2015.10314

Sung G, Ha S, Kwon SB, Kim T (2017) Reduction of ultrafine particles emission from office laser printers. J Aerosol Sci 103:15-23. https ://doi.org/10.1016/j.jaerosci.2016.09.007

Tang T, Hurra J, Gminiski R, Mersch-Sundermann V (2012) Fine and ultrafine particles emitted from laser printers as indoor air contaminants in German offices. Environ Sci Pollut Res Int 19:4233. https://doi.org/10.1007/s11356-012-0889-x

Voliotis A, Karali I, Kouras A, Samara C (2017) Fine and ultrafine particle doses in the respiratory tract from digital printing operations. Environ Sci Pollut Res Int 24:3027-3037. https://doi.org/10.1007/ s11356-016-8047-5
Wallace L, Ott W (2011) Personal exposure to ultrafine particles. J Expo Sci Environ Epidemiol 21:20-30. https://doi.org/10.1038/ jes.2009.59

Wang L, Li M, Yu S, Chen X, Li Z, Zhang Y, Jiang L, Xia Y, Li J, Liu W, Li P, Lichtfouse E, Rosenfeld D, Seinfeld JH (2020) Unexpected rise of ozone in urban and rural areas, and sulfur dioxide in rural areas during the coronavirus city lockdown in Hangzhou China: implications for air quality. Environ Chem Lett. https://doi. org/10.1007/s10311-020-01028-3

World Health Organization (WHO) (2020a) Coronavirus disease (COVID-19) pandemic. https://www.who.int/emergencies/disea ses/novel-coronavirus-2019. Accessed 30 July 2020

World Health Organization (WHO) (2020b) Transmission of SARSCoV-2: implications for infection prevention precautions. https ://apps.who.int/iris/bitstream/handle/10665/333114/WHO-2019nCoV-Sci_Brief-Transmission_modes-2020.3-eng.pdf. Accessed 30 July 2020

Wu CL, Chao CYH, Sze-To GN, Wan MP, Chan TC (2012) Ultrafine particle emissions from cigarette smouldering, incense burning, vacuum cleaner motor operation and cooking. Indoor Built Environ 21(6):782-796. https://doi.org/10.1177/1420326X11421356

Ye G, Lin H, Chen L, Wang S, Zeng Z, Wang W, Zhang S, Rebmann T, Li Y, Pan Z, Yang Z, Wang Y, Wang F, Qian Z, Wang X (2020) Environmental contamination of the SARS-CoV-2 in healthcare premises: an urgent call for protection for healthcare workers. J Infection. https://doi.org/10.1016/j.jinf.2020.04.034

Zhu J, Xie J, Huang F, Cao L (2020) Association between short-term exposure to air pollution and COVID-19 infection: evidence from China. Sci Total Environ 727:138704. https://doi.org/10.1016/j. scitotenv.2020.138704

Zhang M, Zhang S, Feng G, Su H, Zhu F, Ren M, Cai Z (2017) Indoor airborne particle sources and outdoor haze days effect in urban office areas in Guangzhou. Environ Res 154:60-65. https://doi. org/10.1016/j.envres.2016.12.021

Publisher's Note Springer Nature remains neutral with regard to jurisdictional claims in published maps and institutional affiliations. 